came under my notice at Brown's Town, viz. two perfectly black parents having a family all pure albinos.

Kingston, Jamaica, May 26

ThOMAS CAPPER

\section{Singular Behaviour of a Squirrel}

A NEIGHBOUR of mine, whose cottage is thickly surrounded with trees, observed a squirrel, during the severe weather of winter, occasionally stealing food from the troughs set out for the poultry. At first it caused great commotion among the birds, but latterly they were less uneasy in its presence. Taking an interest in the wild creature he began to lay out refuse food for it, including bits of ham, which it greedily appropriated. Getting more courageous, it ventured within doors. After a time it got caught in a trap set for rats underneath the bed. Being freed from its irksome position it was thought that the squirrel would venture no more within doors. Neither the incident of the trap nor confinement for some time within a cage availed to restore to it its original shyness. With the coming of summer its visits have been less regular, but occasionally it looks in still. May not a habit like this, affecting only one out of many, be looked upon as corresponding to a "sport" in the vegetable world, and shed some light on the subject of the domestication of animals? The squirrel seems to have been quite a wild one to start with, for there is no one in the district who had been in the habit of keeping one as a pet.

J. SHAW

Dumfriesshire

\section{Hot Ice}

IN reply to a very interesting letter on this subject recently published in NATURE (vol, xxiii. p. 504) by Dr. Oliver J. Lodge, I wish to express my views of the theoretical and practical possibility of the experiment of Dr. Carnelley. I wish to start from some well-known principles accepted by everybody acquainted with the mechanical theory of heat and its applications. According to these principles the volume " $v$ " (and also the total amount of internal energy) of water can be expressed as a function of its pressure " $p$ " and temperature " $t$ "; $v=f(p, t)$. The form of this function, which we need not discuss here, will change with the state of aggregation, so that we shall have three different equations expressing the volumes of water in the solid, liquid, and gaseous form.

$$
\begin{aligned}
& v=f_{\mathrm{i}}(p, t) \ldots \ldots \text { ice } \quad\langle p \text { and } t \text { being considered inde } \\
& \left.\begin{array}{l}
v=f_{\text {ii }}(p, t) \ldots \ldots \text { water } \\
v=f_{\text {iii }}(p, t) \ldots \ldots \text { vapour }
\end{array}\right\} \quad \text { pendent variables. }
\end{aligned}
$$

Geometrically the volumes of ice, water, and vapour will belong to three different surfaces extending between certain limits. Thus the surface $v=f_{\mathrm{i}}(p, t)$, which represents the volumes of ordinary ice, is situated between the limits $q p, l m$, $m d$; the surface representing liquid water lies between $m n$ and $m d$, though it may be extended a little on either side of these limits, if it applies to water heated or cooled over its regular boiling or freezing temperatures, which are situated along the lines $m d$ and $m^{\prime} n .^{1}$ The values of $p$ and $t$, which belong to $m d$ and $m n$, will satisfy two equations $-\phi(p, t)=0$ and $\psi(p, t)=0$. At these points the water will change its form of aggregation and pass over in the state of saturated vapour along the line $m n$ [equation $\psi(p, t)=0$ ], or into ice along $m d$ [equation $\phi(p, t)=0$ ] in a continuous and reversible way. At any other point, which is not situated on $m n$ or $m d$, water may also be liable to change of aggregation, but this process will not be reversible. The line $m n$, where the surface $v=f_{\mathrm{ii}}(p, t)$ breaks up and liquid water changes into vapour, is the curve of tension of saturated vapour contained in the renowned table of Regnault. The boiling-points of water under varying pressure are situated on $m n$, and may be found by solving the equation $\psi(p, t)=0$. At the point $m\left(p=4^{.6} \mathrm{~mm}, t=-0^{\circ} .0078 \mathrm{C}\right.$. $)$ the line $m n$ terminates, but is continued by $l m$ [equation $\chi(p, t)=0$ ], along which the vaporisation of ice takes place in a reversible way. According to the table of Regnault there is no sudden rupture at the point $m$, the pressure of saturated vapour at $\mathrm{O}^{\circ} \mathrm{C}$. being identically the same, if the vapour is in contact with water or with ice. The differential coefficients $\frac{d p}{d t}$ of the functions

I The surface corresponding to the volumes of aqueous vapour $z=f_{\mathrm{iii}}(p, t)$ is not sketched in the figure, which gives only the projection of the surfaces on the plane of co-ordinates $p$ and $t$, not the real situation of these surfaces in space. The reader will also observe that the limiting lines $m n, n d, l m$, $m k$ are the intersections of vertical cylindrical surfaces ("Uebergangsflächen") with the plane $\&, t$. $\phi(p, t), \psi(p, t)$, and $\chi(p, t)$, or the tangents to the lines $m d$, $m n$, and $m l$ are found by application of Carnot's Theorem to be of the general form $\frac{d p}{d t}=\frac{A r}{\left[s-s_{1}\right][273+t]}[r=$ latent heat; $s$ and $s_{1}=$ the specific volumes of water in two different forms of aggregation].

The point $m$, where $m n, m d$, and $m l$ unite, is of particular interest. J. Thomson called it "the triple point," and Guldberg the "Fällespunkt" of water. Lately (in Berichte, 1880) I ventured to call it the "absolute point of sublimation," not because $I$ wished to introduce a new term for a well-known scientific object, but only to point out some important consequences of the phenomenon just then announced by Carnelley, of which Prof. Lothar Meyer of Tübingen had published an interpretation different from mine. This point $m$, situated $-0^{\circ} 0078 \mathrm{C}$. below the ordinary freezing-point of water, is really the upper limit of sublimation, because at any higher temperature ice first changes into water before it evaporates. At $-0^{\circ} \cdot 0078 \mathrm{C}$, where the boiling- and melting-point of water coincide, a real sublimation of ice begins, provided that the barometric pressure does not exceed $4^{\circ} 6 \mathrm{~mm}$. ( $=$ "the critical pressure " of Carnelley).

Now according to the discovery of Dr. Carnelley, ice at pressures lower than $4^{.6} \mathrm{~mm}$. would exist by temperatures up to $+178^{\circ} \mathrm{C}$. Thus the surface $v=f_{\mathrm{i}}(p, t)$, which we have hitherto supposed to be inclosed between the limits $q p, q l, l m, m d$ would exíend far beyond $l m$ nearly up to $k$, but always at pressures smaller than $4^{\circ} 6 \mathrm{~mm}$. Geometrically this new and unforeseen

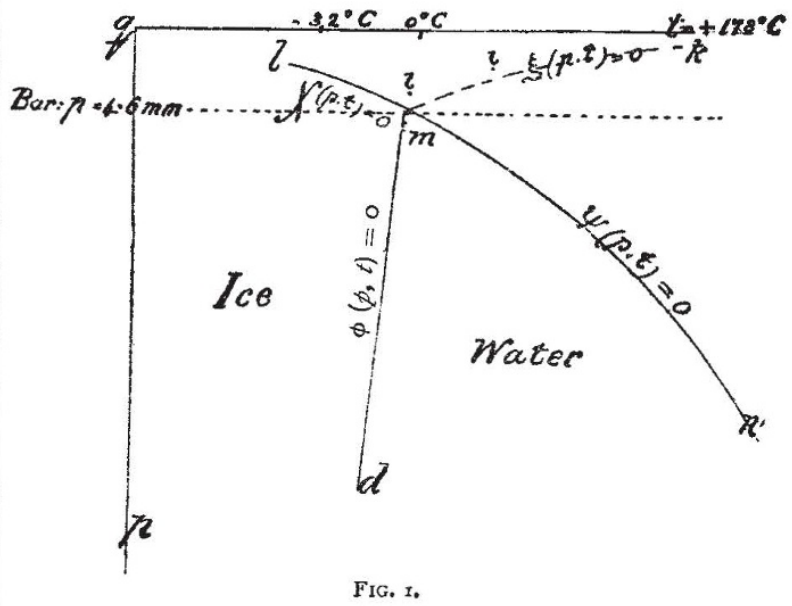

extension of the surface of ice is represented by the area $l m k$. Here the process of Carnelley, whereby ice of low pressure is heated to astoundingly high temperatures, would go on. The area $l m k$ would of course be entirely a terra incognita to the science of the present day, but there is nevertheless no theoretical objection why the surface of ice $v=f_{\mathrm{i}}(p, t)$ should not extend farther than to the limiting line $l \mathrm{~m}$ pointed out by Regnault. Confiding in the experimental proofs already furnished by Dr. Carnelley, I concluded (Berichte, 1880): if the surface of ice really extends upwards to about $+\mathrm{I} 78^{\circ} \mathrm{C}$, there must be a limiting line $m k$ to the area $l m k$, since this area "cannot extend so far as to the dotted line in the figure indicating the critical pressure $=4^{.} 6 \mathrm{~mm}$. At this new limit, $m k$, corresponding to an equation $\xi(p, t)=0$, the vaporisation of the "hot ice" may go on in a reversible way, just as liquid water gives up saturated vapour at those pressures and temperatures which belong to the line $m n$ (equation $\psi(t, p)=0$ ). The line $m k$ would in many respects be the continuation of $m d$ (just as $m l$ forms the continuation of $m n$ ), but naturally the syml ols entering the equation of its differential coefficient $\frac{d p}{d t}=\frac{d r}{\left(s-s_{1}\right)(273+t)}$ must change their signification on the other side of the point $m$, so that $r$ here would represent the latent heat of vaporisation of the hot ice, $s$ its specific volume, \&c. I did not expressly mention this in my paper in the Berichte, because I thought it unnecessary. This omission on my side may probably have misled Dr. O. Lodge as to the real meaning of my words, since he declares my opinion that an equation $\xi(p, t)=0$ having a differential 